\title{
No vórtice de Ubu
}

\section{Paulo Eduardo Carvalho}

Titulo: UBUs: Um contributo para a desdramatização da pátria. Autor: Alfred Jarry (a partir de vários textos). Tradução e dramaturgia: Luisa Costa Gomes. Encenação: Ricardo Pais. Cenografia: Pedro Tudela. Figurinos: Bernardo Monteiro. Canções: Sérgio Godinho. Desenho de luz: Nuno Meira. Desenho de som: Francisco Leal. Criação e preparação rítmica: Miquel Bernat. Coreografias tradicionais: Margarida Moura. Consultoria mágica: Luis de Matos. Lutas e marchas militares: Miguel Andrade Gomes. Preparação vocal e elocução: João Henriques. Assistência de encenação: Nuno M. Cardoso. Interpretação: Alberto Magassela, António Durães, Emilia Silvestre, Ivo Alexandre, Joana Manuel, João Castro, João Reis, Jorge Vasques, Ligia Roque, Micaela Cardoso, Paulo Freixinho, Pedro Almendra, Pedro Pernas e António Sérgio. Produção:Teatro Nacional S. João. Local e data de estreia: Teatro Carlos Alberto, Porto, 16 de Abril de 2005.

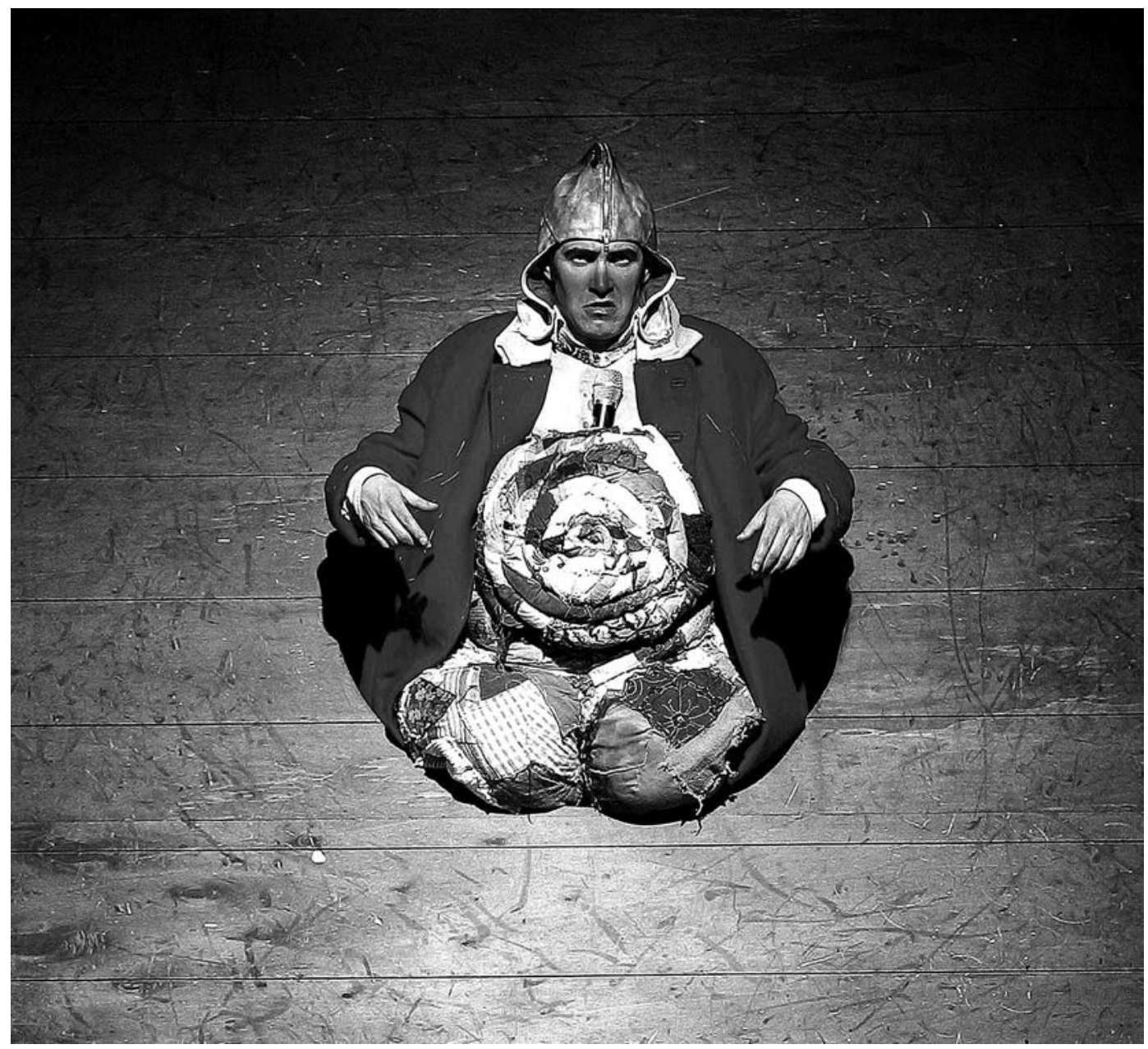

A utilização de plurais nos títulos de alguns dos espectáculos encenados ou dirigidos por Ricardo Pais funciona, por vezes, não só como reafirmação de um entendimento da cena como "lugar de uma pluralidade sensorial, sonora e visual", mas também como indiciadora de um gesto de mais assumida apropriação de objectos dramatúrgicos pré-existentes. Foi assim, notavelmente, em 1998, com As lições - espectáculo que ampliava a breve peça de lonesco, de 1951, com a ajuda de outros textos de Georges Feydeau,
Ramalho Ortigão, Guerra Junqueiro e Ernesto Sampaio, bom como com um conjunto ousado de manobras cénicas - e é, agora, assim com o mais recente UBUs, acrescido de uma provocação erguida à condição de discreto subtítulo - a contradição é voluntária -, "Um contributo para a desdramatização da pátria".

Com tradução e dramaturgia - que costuma ser palavra maldita nos espectáculos de Ricardo Pais... - de Luísa Costa Gomes, este UBUs enxerta em Rei Ubu elementos 
de diversa consequência e importância dos outros ciclos da Gesta de Ubu, tal como Alfred Jarry a foi gizando a partir de 1888, caso de Ubu cornudo e Ubu no outeiro. Destas e doutras operações nos dão conta: o generoso Manual de Leitura do espectáculo, 36 páginas que reúnem diversos contributos originais para o conhecimento da influente obra de Jarry (para além das conversas de José Luis Ferreira, Ricardo Pais, Luísa Costa Gomes e António M. Feijó, ainda os textos inéditos de Fernando Cabral Martins, Vitor Silva Tavares, Saguenail, João Lisboa, João Sousa Cardoso, e outros documentos históricos, traduzidos, do próprio Jarry e de André Breton), bem como a publicação desta nova tradução portuguesa das quatro peças da referida "gesta", na colecção de teatro da Campo das Letras (acrescenta-se às já referidas ainda Ubu agrilhoado, só ficando de fora Os almanaques de Ubu). Todo este esforço editorial traduz um entendimento consciente e consequente do papel que pode ser desempenhado por um Teatro Nacional - e só poderá ser de lamentar que, nos últimos anos, não tenha sido possivel aplicar o mesmo tipo de prolongamento a outras produções daquela casa.

Nos muitos "diálogos" por onde se distribuem as declarações do encenador sobre este espectáculo, esclarecese que o projecto original passara pela ideia de uma '"ubuzada', uma espécie de grande Cabaré Ubu", construido, de forma mais fragmentária, a partir de cenas retiradas dos diversos Ubus. Tal como o criador confessa, "tinha pensado em fazer um espectáculo de variedades puro e duro" - e, embora involuntária, não será menos produtiva a contraditória escolha de adjectivos para caracterizar a lógica de "variedades" tantas vezes reclamada por Ricardo Pais para os seus espectáculos. Dessa pulsão original, UBUs conserva como marcas mais óbvias a introdução de canções, compostas expressamente para o espectáculo por Sérgio Godinho, e alguns momentos mais assumidamente coreografados, com a colaboração de Margarida Moura. 0 espectáculo inclui ainda, para além de um marcante desenho de som de Francisco Leal, uma constante presença musical, ao vivo, quase praticamente limitada à utilização de percussões, criadas e preparadas por Miquel Bernat. Embora certamente diversa da original, a proposta do espectáculo continua, assim, a ser eminentemente musical, e para isso contribui decisivamente a proficiente versatilidade de todos os "intérpretes-actores", pois por eles passa não só o texto de Jarry, mas também todos os outros múltiplos gestos e linguagens cuja articulação o encenador Ihes confia.

Esta explícita dimensão sonora e musical surge sugestivamente sinalizada por dois dos elementos mais destacados do espaço cénico proposto por Pedro Tudela: dois enormes postes ou mastros de madeira, na extremidade dos quais florescem uns gigantescos altifalantes, que servem como efectiva fonte sonora - inclusive das vozes explicitamente amplificadas dos intérpretes, que arrastam consigo, pendurados na sua roupa, e ao longo de todo o espectáculo, volumosos microfones de mão -, embora também ajudem à leitura do imenso relvado artificial que invade o palco e a primeira plateia do Teatro Carlos Alberto como o espaço de um terreiro, de uma feira ou arraial popular. Sobre esta vasta paisagem surgem ainda uma estrutura de ferro (recuperada de uma anterior intervenção do artista no Salão Nobre do TNSJ) e uma plataforma de madeira, apoiada, não obstante a sua imobilidade, numas enormes rodas, espécie de velha carroça ou cadafalso, que acaba por funcionar como um pequeno, mas infinitamente versátil, palco-dentro-do-palco. Mais explicitamente duchampianas são as retretes mobilizadas que figuram o gesto escatológico da ficção de Jarry, abrindo-se a jogos e combinatórias infinitas, até à sua transformação final em suportes de uma organizada e artificial beleza. Lúdicos e provocatórios são também alguns dos adereços que, a espaços, invadem a cena, como as costeletas de murgalho ou as armas dos guerreiros em forma de pénis artificiais.

Como se sugere por esta evocação sumária do espaço de representação - animado pela luz discreta, mas

"indispensável", de Nuno Meira -, não estamos, ao contrário do que tantas vezes acontece nos espectáculos de Ricardo Pais, face a uma aglutinadora metáfora cénica, motivadora de uma mais codificada e até rígida utilização do espaço, mas antes (como também, por vezes, tem acontecido noutras aventuras cénicas daquele criador), no domínio de um território, de uma paisagem, igualmente rica nas suas sugestões, mas mais aberta na sua exploração e na organização de sinais que propõe ou a que obriga.

A minimal ruralidade sugerida pela cenografia encontra expressão mais eloquente nas opções assumidas pelos figurinos de Bernardo Monteiro, que articulam uma lógica de colagem de farrapos e outros fragmentos com uma revisitação paródica - tão distanciada quanto enamorada - de muitos dos motivos do vestuário tradicional português, tal como o possamos recordar de algum vago folclorismo ou de mais sofisticadas e eruditas apropriações anteriores, muitas delas de amplas ressonâncias ideológicas. Os figurinos acabam, aliás, por assumir um raro papel estruturante neste espectáculo, não só porque são eles que explicitam, com rara capacidade lúdica, a provocação contida na ideia de pátria para cuja desdramatização se pretende contribuir - na transferência de uma Polónia que é "parte nenhuma" para um Portugal que, assim, se convoca de forma burlesca e rigorosa -, mas também porque são eles que melhor sinalizam aquele espaço como um lugar de representação cujos protagonistas são "fantoches". 0 figurino volumoso de Dom Ubu recupera com engenho e surpresa o conhecido desenho de Jarry da sua personagem, convertendo a espiral colocada sobre o seu ventre na imagem do vórtice sinistro que será o percurso do seu portador. Por seu lado, o imaginativo e complexo dispositivo criado para as três Donas Ubu deste espectáculo oferece-se quase como metáfora do jogo cénico proposto, ao recuperar simultaneamente o exagero (sexual e escatológico) e as limitações articulatórias do boneco de fantoches, para o investir de uma inusitada expressividade e versatilidade.

Sem surpresa, o núcleo expressivo do espectáculo 


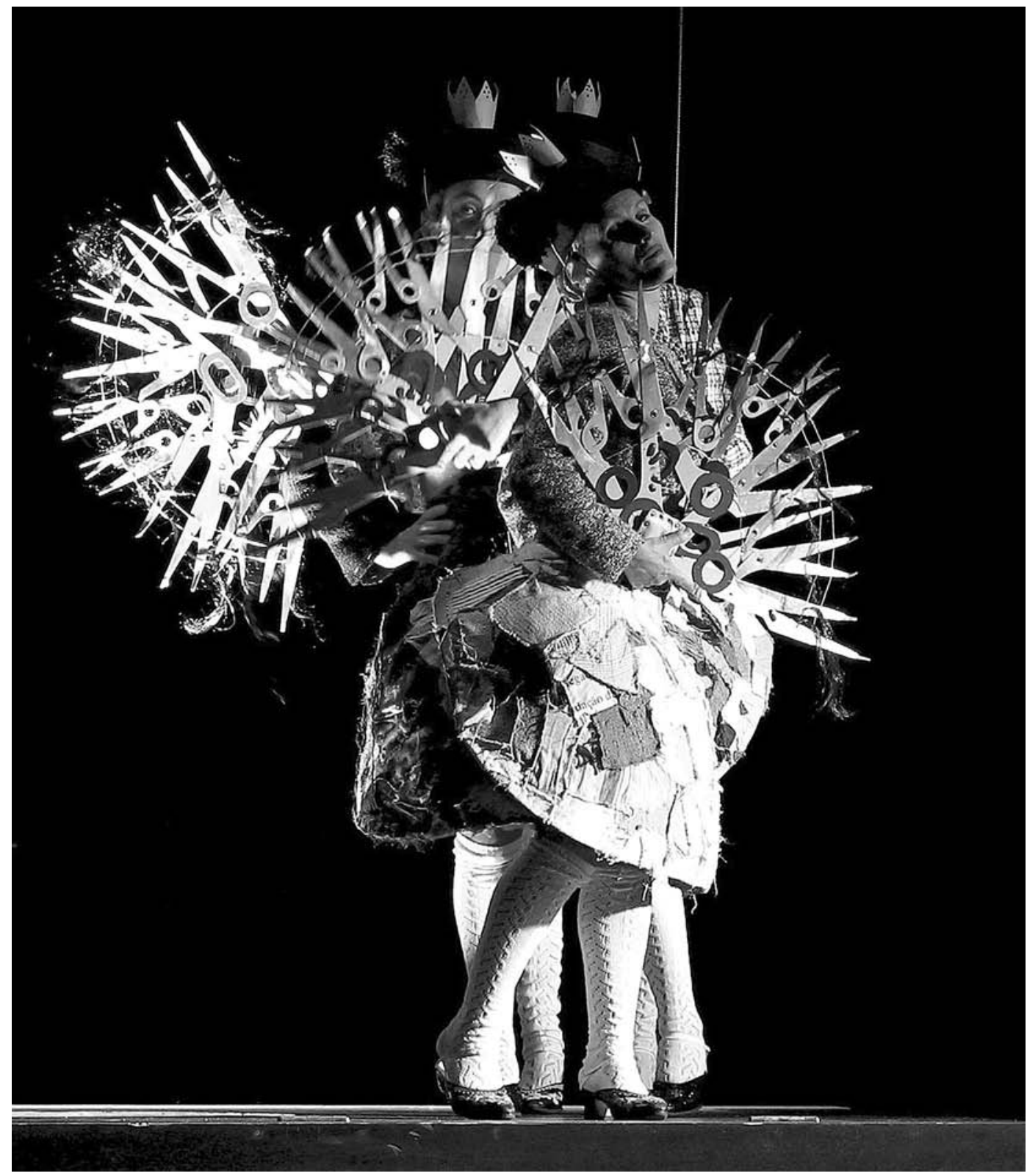

UBUS,

de Alfred Jarry, enc. Ricardo Pais, TNSJ, 2005 (Emilia Silvestre, Ligia Roque e Micaela Cardoso), fot. João Tuna. está concentrado no conjunto de catorze intérpretes, convocados a dizer, a tocar, a cantar, a dançar, a lutar e a assegurar uma interacção exigente com as complexas valências dos continuamente renovados dispositivos e sinais cénicos. João Reis dá corpo e voz a um inesquecivel Dom Ubu, num trabalho em que o virtuosismo vocal (já esplendorosamente confirmado em As lições) se alia, aqui, a uma capacidade nova de relação interpretativa com a sua personagem: aquilo a que se assiste, ao longo das quase duas horas da sua presença em cena, é a um progressivo distanciamento quase irónico do intérprete relativamente ao protagonista desta ficção, sinalizado no modo como, a dada altura, a "personagem" assume o comando das acções dos outros intérpretes (isto é particularmente notório num dos momentos de execução instrumental), mas também numa mais ampla atitude física, vocal e facial. Emília Silvestre, Micaela Cardoso e Ligia Roque asseguram exemplarmente a homogeneidade expressiva das suas intervenções como Donas Ubus. Curiosamente, aquilo que poderia parecer uma simples "ideia engraçada" - desdobrar a personagem da Dona Ubu por três actrizes - acaba por ser explorado não só em benefício da clarificação narrativa da ficção, uma vez que a sua sucessão corresponde aos três grandes momentos do trajecto de Ubu (usurpação do trono da Polónia, reinado de terror e, por fim, a guerra), mas também da própria natureza paródica do texto de Jarry. Recorde-se que três são também as bruxas que dilatam a ambição de Macbeth, protagonista shakespeariano de uma outra história de terror e tirania que serviu assumidamente de intertexto ao autor da peça, e que o encenador explora figurativamente logo nos primeiros momentos do espectáculo: durante o primeiro diálogo do casal Ubu - "Não é a mim Dom Ubu, mas a outro que é preciso assassinar" -, ao fundo, sobre a carroça, estão colocadas as outras Donas Ubus, munidas dos seus burlescos leques de tesouras, iluminadas como espectros através do buraco que se irá revelar como o mais explorado dos recursos cénicos de todo o espectáculo.

Embora o destaque devesse estender-se a todos os demais intérpretes, nas suas múltiplas e variadas corporizações - confirmando os esforços formativos desenvolvidos por aquele Teatro -, limito-me a registar ainda os contributos 


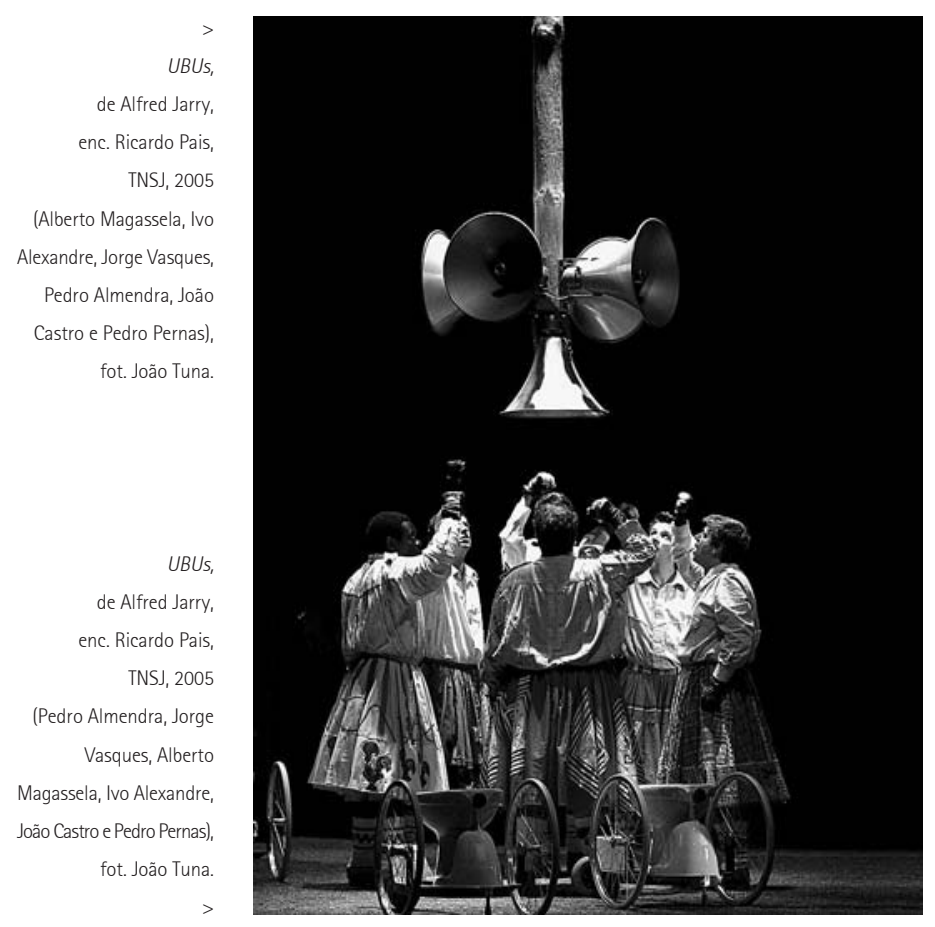

de Joana Manuel, particularmente na musical intervenção

de Alfred Jarry, enc. Ricardo Pais,

TNSJ, 2005

(Ligia Roque, João Reis António Sérgio), fot. João Tuna. da Rainha Rosimunda, viúva do assassinado Venceslau, de António Durães, no papel do mesmo patético Venceslau, e de Paulo Freixinho, num tão enérgico como volátil Capitão Bostura.

0 encenador dedica o espectáculo a Alexandre O'Neill - "que nos espreita trocista, de uma janelinha do Palácio dos Imortais Patafísicos" -, primeiro tradutor e adaptador, com Luís de Lima, deste mesmo Rei Ubu, nos já longínquos anos sessenta, e colaborador de Ricardo Pais noutras e mais antigas aventuras, como A mandrágora (1976) e Ninguém (1978), e sujeito de uma relação complicada com Portugal, feita de sobranceria, mas também de um sofrido enamoramento. Mas o poeta da "feira cabisbaixa" e da "pequena dor que cada um de nós / traz docemente pela mão" foi também o poeta de uma defesa ardente da imaginação: "Imaginar, primeiro, é ver. / Imaginar é conhecer, portanto agir". Por seu lado, Jarry apresenta a sua Patafísica como "a ciência das soluções imaginárias que confere simbolicamente aos traços gerais as propriedades dos objectos descritos pela sua virtualidade", definição que no seu lúdico enigma encerra um repetido convite à perturbação do equilíbrio das lógicas racionais, que tanto inspiraria as vanguardas do primeiro modernismo e o movimento surrealista. Em lugar da recuperação das problemáticas avançadas em finais do século XIX com a criação de Rei Ubu, terá interessado antes a Ricardo Pais, neste circuito de homenagens e neste espectáculo atravessado igualmente por uma tão intensa quanto produtiva auto-citacionalidade -, reafirmar um processo criativo no qual o desafio imaginativo surge respondido por uma lógica de excesso, a única, aliás, capaz de conferir alguma "beleza" a um repositório tão monstruoso de paixões sinistras como este Ubu.

Como já se poderá ter percebido, estamos no domínio mais potencialmente sedutor dos procedimentos cénicos de Ricardo Pais, em que a cena se abre generosamente aos contributos das outras artes e linguagens, propiciando uma espécie de vertigem ou de "voracidade" onde uma
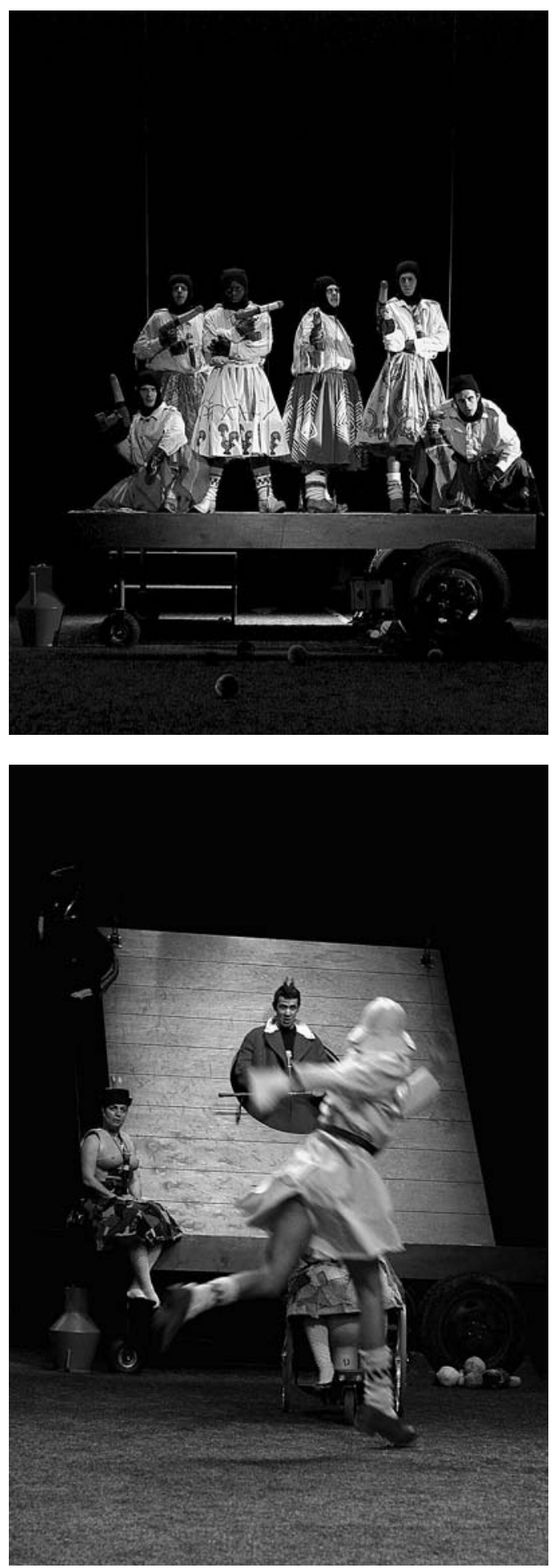

procurada libertinagem se combina com um não menos obsessivo rigor e seriedade. Mais do que um conjunto de ideias engraçadas, ou de trouvailles, eventualmente ao serviço de um qualquer complacente, por muito profissional, exercício de estilo, o que esta arriscada estratégia cénica propicia, nomeadamente neste caso, é uma espécie de corporização dos próprios desafios e convites passiveis de serem lidos no projecto dramatúrgico de Jarry: uma espécie de renovação da utopia de um teatro que entende a criação como um processo em que se fundem a mais ousada irrisão com a mais empenhada das vontades de comunicar. 